Revista del Centro de Investigación de la Universidad La Salle

Vol. 13, No. 51, enero-junio, 2019: 41-66

DOI: http://dx.doi.org/10.26457/recein.v13i51.1867

\title{
"Estamos de paso". Informalidad y ciudadanía precaria como proceso de despolitización: El caso del emporio comercial Gamarra en Lima (2012-2018)
}

\section{"We are passing through." Informality and precarious citizenship as a process of depoliticization: the case of Gamarra commercial emporium in Lima (2012-2018)}

Moisés Rojas

Universidad Peruana de Ciencias Aplicadas (Perú)

José Luque ${ }^{1}$

Universidad Autónoma de la Ciudad de México (México)

Recibido: 02 de mayo de 2019

Aceptado: 22 de noviembre de 2019

Publicado: 13 de diciembre de 2019

\section{Resumen}

El presente artículo explora las consecuencias de la informalidad en la configuración de una ciudadanía precaria referida al emporio comercial de Gamarra, el más importante del Perú, ubicado en su capital, Lima. La idea central que estructuró al trabajo sostiene que

\footnotetext{
${ }^{1}$ Email: jose.luque@uacm.edu.mx
}

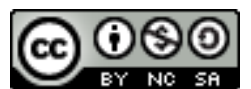

Revista del Centro de Investigación. Universidad La Salle por Dirección de Posgrado e Investigación. Universidad La Salle Ciudad de México se distribuye bajo una Licencia Creative Commons Atribución- 
la informalidad precaria, precisamente desde la experiencia del tiempo -donde los trabajadores se sienten "de paso" - , despolitiza a los pobre urbanos. Debido a que los trabajadores no se apropian del lugar y no buscan cuestionar las condiciones de explotación en las que trabajan que violan sus derechos de ciudadanía, principalmente los sociales. En este sentido, la pregunta que guio la investigación fue: ¿cómo despolitiza la informalidad precaria a los trabajadores del emporio Gamarra desde la experiencia del tiempo? Metodológicamente, los datos se construyeron desde una investigación cualitativa de carácter etnográfica, la cual se ubicó sobre los contextos de cuatro tipos de trabajadores informales: ambulantes, talleristas, jaladores y vendedoras. El arco de tiempo acotado fue del período 2012-2018.

Palabras clave: informalidad precaria, Gamarra, experiencia del tiempo, dominación, despolitización 


\section{Abstract}

This article explores the consequences of informality in the configuration of precarious citizenship referred to the commercial empire of Gamarra, the most important informal market in Peru, located in its capital, Lima. The central idea that structured this work argues that precarious informality, precisely because of the experience of time - where workers feel that they work is temporary- depoliticizes the urban poor because workers do not appropriate the place and do not seek to question the conditions of exploitation in which they work which violate their citizenship rights, mainly social rights. In this sense, the question that guided the investigation was: how does it depoliticize precarious informality for the workers of the Gamarra emporium from the experience of time? Methodologically, the data that was constructed from qualitative ethnographic research, which was located in the contexts of four types of informal workers: street vendors, workshop workers, shooters, and vendors. The limited-time arc was from the 2012-2018 period.

Keywords: precarious informality, Gamarra, temporary experience, domination, depoliticization. 


\section{Introducción}

A comienzos de la década de los setentas del siglo pasado, el economista Keith Hart, publico el artículo: "Informal Income Opportunities and Urban Employment in Ghana", en el Journal of Modern African Studies, dicho estudio, caracterizó los elementos constitutivos de la "informalidad": "The distinction between formal and informal income opportunities is based essentially on that between wage-earning and self-employment. In practice, informal activities encompass a wide-ranging scale, from marginal operations to large enterprises; whether their productivity is relatively high or low remains a question for empirical verification". (Hart, 1973: 68), La peculiaridad de los aportes de Hart consistieron en revelar un conjunto de actividades productivas que realizaban las personas pobres entre oficios y tareas a pequeña escala y -sin ser actividades delictivas- que se hacían fuera de las reglas y procedimientos institucionales, asimismo estás actividades tenían un amplio arco de desarrollo, estaban aquellas dedicadas a la sobrevivencia hasta importantes negocios rentables, pero que compartían los siguientes elementos: No eran reconocidas por las autoridades, no estaban registradas, no generaban derechos sociales y no estaban reguladas por el estado.

Desde el estudio seminal de Hart han pasado más de 45 años y la informalidad es un fenómeno que se incrementó, globalizó y desplego en la era neoliberal. Actualmente, la informalidad laboral es un fenómeno multidimensional gravitante en América Latina que afecta profundamente los derechos sociales en la región. Según la Organización Internacional del Trabajo (OIT), para el año "2016, 140 de los 263 millones de trabajadores de la región tenían empleos informales." (Salazar-Xirinachs y Chacaltana, 2018: 9). Un indicador alto para una región de ingresos medios en el concierto mundial, ello tiene serias consecuencias para los derechos sociales, significa que al menos hay en la región 140 millones de personas trabajando sin contratos, sin condiciones mínimas de calidad laboral, ni beneficios sociales.

Por lo expuesto anteriormente se puede afirmar que la informalidad laboral es un fenómeno de gran alcance y uno de los elementos que sintetizan la relación entre ciudadanía, estado y neoliberalismo en la región. Entonces, ¿no es también importante estudiar sus implicancias políticas y de poder? Este artículo, a partir de un trabajo de campo de despliegue etnográfico, se pregunta: ¿qué tipo de ciudadanía se construye desde 
el contexto de la informalidad y cómo se estructura? Centrándose específicamente en la experiencia del tiempo que perciben los individuos instalados en la informalidad.

Nuestro caso de estudio se situó en "Gamarra", el emporio comercial y productivo de ropa más importante de Perú, donde trabajan actualmente 80 mil personas. Su protagonismo inició a mediados de la década de los noventas del siglo pasado, cuando "un gran número de pequeñas empresas de confección que tras el Ajuste Estructural sobrevivieron a la liberalización y la desregulación se aglomeraron en el centro industrialcomercial de Gamarra en La Victoria, consolidándose un centro, inicialmente de manera informal (...) con alta capacidad de innovación y de organización que puede conectarse a redes internacionales y afrontar la creciente competencia externa (González y Del Pozo, 2012: 43), dicho ajuste estructural fue impulsado por el primer gobierno de Alberto Fujimori, el cual inicio su recorrido político elegido en las urnas y termino transformándose en una dictadura con el golpe militar de abril de 1992 (Pease, 2003: 16) . Se estima que un $70 \%$ de los trabajadores que concurren a este emporio lo hacen en condiciones de informalidad laboral (Rojas, 2014).

Gamarra surgió en los 70's resultado de los cambios estructurales y reformas impuestas por la dictadura militar conducida por el General Juan Velasco Alvarado (1968-75), las reformas laboral, agraria y educativa fueron fundamentales en ese sentido, la reforma agraria destruyo los sistemas latifundistas, la reforma educativa combatió los órdenes culturales oligárquicos y la laboral doto de derechos laborales a los trabajadores, ello generó obviamente un proceso de politización de los sectores populares, la migración del campo a la ciudad y la introducción del modelo de desarrollo por sustitución de importaciones (MSI), este proceso político entra en dificultades por el tema de la deuda externa y aparece la crisis del desempleo (Pease, 2003: 30), crisis que empujó a miles de migrantes que apenas llegaban a Lima, durante la segunda parte de la dictadura militar (1975-1980), conducida ahora por el General Francisco Morales Bermúdez, a trabajar "como sea", con tal de obtener algunos ingresos que les permitan sobrevivir en la ciudad. En el Perú, Gamarra, es un caso emblemático en el debate público en el Perú, ya que es un caso que comprueba los principios neoliberales y el capitalismo popular, basados en la tesis del “orden espontáneo". (Gray, 1993).

Por otro lado, desde los debates sobre el Estado, la bibliografía predominante se ha aproximado a la informalidad precaria desde el enfoque del enforcement o capacidad 
estatal. El Estado no entraría a estas zonas por una incapacidad de hacer cumplir las normas. Desde nuestras referencias teóricas, por el contrario, la no regulación podría ser más bien expresión de su eficiencia política, de cierta capacidad política del Estado para precarizar la ciudadanía de los pobres urbanos y a su vez contenerlos políticamente. Algunos autores como Max Cameron y Juan Pablo Luna (2010), están desarrollando el concepto de las "oligarquías" dentro de la democracia y en el neoliberalismo, para dar cuenta de cómo las dinámicas políticas van creando sistemas de exclusión de la participación política. La informalidad precaria sería parte funcional de las nuevas “oligarquía" - exclusiones- dentro del neoliberalismo. Allí donde cierta bibliografía ve "ineficiencia administrativa" sobre la informalidad, desde esta investigación partimos de proponer cierta "eficiencia política". (Auyero, 2009).

¿Gamarra es el paraíso de la informalidad y del capitalismo popular? Las respuestas encuentran enormes matices cuando uno se acerca a las dinámicas laborales de Gamarra. En esos escenarios no es raro encontrarse con trabajadores que trabajan más de 10 horas al día, que trabajan sin condiciones mínimas de seguridad, que no firman contratos, que reciben salarios bajos, sin derechos sociales, contraponiendo la propuesta teórica que asume una condición estructural y relacional entre derechos civiles, políticos y sociales (Marshall y Bottomore, 1992), Es decir, a mayor precariedad, menores capacidades de ciudadanía política activa y de cristalización de los derechos sociales asociados con el trabajo (seguro social, jornada laboral, jubilación, etc., entre otros), pero lo que más llama la atención es que, a pesar de las condiciones de precariedad, en los más de 50 años de funcionamiento de Gamarra, hasta el día de hoy, no ha habido una sola acción colectiva de reclamo o de exigencia de derechos laborales. ¿Qué tiene Gamarra -o qué funciona en él一 para que los principales afectados del desarrollo del capitalismo peruano no sean reales actores políticos?

Este articulo construyó una clasificación de los trabajadores informales de Gamarra: Ambulantes, vendedoras, talleristas y jaladores, analizando sus procesos de despolitización desde su experiencia del tiempo. Nuestra hipótesis de trabajo sostiene que se han generado horizontes temporales de desarraigo que despolitizan a los trabajadores informales. Si este fuese el caso, la informalidad entonces sería una suerte de máquina de dominación, que produce sujetos despolitizados. Estaríamos entonces ante un caso de capitalismo de chupacabras que despolitiza a los ciudadanos hasta transformarlos en objeto del mercado (Gálvez y Luque, 2019). Proponemos teorizar a la informalidad como 
un sistema perverso y circular de dominación de los más pobres del Perú, específicamente de Lima.

\section{Apartado metodológico}

Metodológicamente, se utilizaron dos técnicas de investigación cualitativas: La etnografía y las entrevistas semi-estructradas. La etnografía se desplegó a lo largo del segundo semestre del 2017, proceso durante el cual se recopilaron cerca de mil hojas de descripciones de vida cotidiana laboral; y más de 70 entrevistas semi-estructuradas a los diferentes tipos de trabajadores, las entrevistas culminaron cuando se llegó al punto de saturación de los contenidos y la técnica de reclutamiento de los informantes fue el de la bola de nieve. La etnografía ha cruzado observaciones no participantes, como ejercicios de observación participantes, en las que hemos simulado ser trabajadores para aproximarnos lo más posible a la experiencia laboral de los trabajadores informales del emporio Gamarra. El análisis empleado de la información se realizó en base a los ejes temáticos de la investigación: desarraigo del tiempo, informalidad y despolitización.

Obviamente en el presente artículo sólo se ocupó una pequeña parte del material levantado durante el trabajo de campo.

\section{Referencias teóricas}

\subsection{Miradas sobre la informalidad}

Es conveniente evaluar cuál ha sido el debate peruano sobre este tema, lo cual es importante por dos razones: para la bibliografía internacional, el Perú ha sido origen de al menos dos clásicos de los estudios de la informalidad: Hernando de Soto (1987) y Aníbal Quijano (1977 y 1998). Uno desde una postura liberal y el otro desde una postura crítica. Además, porque el Perú es uno de los casos más enfáticos de informalidad laboral en la región latinoamericana y podría ser un foco de análisis aplicable a otros países similares.

Entonces analizaremos, junto con los ya mencionados, a José Matos Mar (1980 y 2012), Romeo Grompone (1985), Francisco Durand (2007) y Danilo Martuccelli (2015). Ellos han sido los principales investigadores de la informalidad peruana y que poseen en su desarrollo una marcada diferencia en su forma conceptual y metodológica de ver el fenómeno que aquí también investigamos. 
Para comenzar, entre los investigadores mencionados no existe un consenso sobre la adopción del concepto de la "informalidad". El uso mismo del concepto es cuestionado. Discrepan marcadamente Grompone y Quijano. Quijano tiene una postura crítica al capital global. Para él son parte del "ejército industrial de reserva" que queda excluida de la economía. Quijano los llamó "polo marginal”. La marginalidad, entonces, "es un fenómeno producido por las propias tendencias globales del capital, cuyos efectos sobre la población trabajadora se ejercen en todo el universo capitalista, pero que se agravan en las condiciones de una sociedad 'dependiente"” (Quijano, 1998: 69). Y los conforman el conjunto de actividades que se llevan a cabo en torno a recursos residuales de producción, los que se estructuran como relaciones sociales de modo precario e inestable. Es así que "genera ingresos reducidos, inestables y de incompleta configuración respecto del 'salario' o de la 'ganancia' [...]. Predominantemente producen bienes o servicios para un mercado constituido por la propia población de trabajadores 'marginados"” (70).

Grompone critica esa mirada de la marginalidad por entender que esta "población [...] es 'secretada' por cada uno de los sectores económicos y por cada una de sus ramas. En un razonamiento que evoca la alegoría de la caverna, aquello que no surge desde la lógica predominante del sistema está condenado a ser su sombra o su espectro" (Grompone, 1985: 46). Principalmente se opone por las siguientes razones:

- Crea una dicotomía: "En lugar de un continuo de actividades urbanas asalariadas y no asalariadas, se establece un corte" (Grompone, 1985: 51).

- Esconde un mundo heterogéneo de trabajos en la ciudad. Cuestiona la "hipersimplificación" en la que cae el concepto de informalidad en su búsqueda de "vacuas simplificaciones".

- Es una abstracción no justificada que ordena la economía en un modelo sectorial, como si la informalidad y la formalidad fueran dos bloques.

- Y quizá lo más interesante: "Y lo que queda escamoteado en el análisis son los actores, los agentes económicos, las clases, las personas o como quiera denominárselas, absorbidos en una construcción general que se presume que habla de ellos, pero que en realidad pretende ocultarlos" (Grompone, 1985: 52). 
Tanto De Soto, Matos Mar, Durand y Martuccelli usan el concepto de "informalidad". No obstante, lo hacen de forma diferenciada. De Soto (1986) muestra el rostro positivo de la informalidad. Se trataría de la expresión de destrezas, habilidades, capacidades y competencias del sector popular, pero contenidos por un Estado ineficiente y políticamente mercantilista. Critica al Estado porque supuestamente se pone del lado de los intereses de grupos de poder y excluye a los informales. Es el que construye trabas: “impiden el acceso de la gente humilde a la sociedad formal”.

Matos Mar (2012, 1980), por su parte, ubica el asunto dentro de una relación centro y periferia del Perú, ya que los informales estarían inscritos en el fenómeno de la migración de las provincias hacia la capital, Lima. La informalidad para el mencionado autor es en realidad el proceso de desafío del centro por parte de los provincianos. Asimismo, agrega: "Millones consiguieron en pocas décadas tener éxito y ser ciudadanos limeños y peruanos, tener vivienda propia en la capital del Perú, sede el poder nacional, tener trabajo informal o formal, legal o no, crear un estilo económico contestatario, modernizarse por su propio esfuerzo y convertirse en un gran conjunto de sectores populares y medios, y en actores de la modernidad que vivía limitadamente el Perú”. (Matos Mar, 2012: 252).

La mirada de Matos Mar recae en la descripción del acceso al suelo por parte de los migrantes que desde la década de 1940 comenzaron a llegar masivamente a Lima. La ciudad se gesta desde las barriadas que, en su análisis, representa un reencuentro histórico del Perú oficial con el otro Perú, el acceso al mercado de consumo y de trabajo, el escape de la pobreza extrema rural, la conquista de la ciudadanía y la pluralización cultural de la ciudad (Matos Mar, 2012: 246-252). Es una aproximación, bastante optimista y celebratoria.

Francisco Durand (2007), en El Perú fracturado, no cuestiona el concepto de la informalidad; por el contrario, le agrega un tipo de economía más: la delictiva. Su enfoque es tricotómico. Según el autor, existen tres economías no excluyentes entre ellas, sino más bien con continuidades y múltiples interacciones. La postura de Durand contiene una mirada crítica, no desde el marxismo, como se veía en Quijano, sino desde una crítica al Estado por su incapacidad a la hora de imponer la informalidad al conjunto de la sociedad: "Lo formal no rige, el Estado no manda" (Durand, 2007: 38). De modo que la informalidad sería un obstáculo para lograr ese ideal de Estado, de sociedad y de nación. 
La informalidad habría producido un desvío y por ello habría generado una "modernidad desviada".

Martuccelli (2015) tampoco cuestiona el concepto de informalidad, pero le da un giro mucho más culturalista. Sería un imaginario, considerando que la informalidad es una "matriz de representación hegemónica", que es compartido por todos los limeños, y que define una particular relación con las normas. Si en otras sociedades se ficciona el orden legal, dice el autor, lo que es esencial para la integración y la igualdad, en el Lima se ficciona lo informal. Lo informal es central y es un aparato integrador. A diferencia de las sociedades donde el mito del orden es central: "El marco ficcional en Lima es casi inverso. El imaginario colectivo sostiene la ficción de una sociedad en donde la ley se modula siempre en función de las personas, de los contextos, de las redes y de los poderes en presencia" (Martuccelli, 2015:168). Es así que la informalidad se habría convertido en el gran imaginario de lazo social en la ciudad.

¿Cómo explican la informalidad estos autores? Es evidente que las razones, todos lo reconocen, son múltiples y de diferente orden. Aquí solo se señalar la explicación más enfática y frecuente para cada uno de los autores en cuestión. Para Quijano (1977), por ejemplo, esta nace por la dependencia a los países centrales y por la naturaleza del capitalismo de producir "marginalidad". Su enfoque es económico dependentista. Matos Mar (1980), por su parte, desde un enfoque territorial que diferencia el centro y la periferia, argumenta que es resultado de la exclusión del otro Perú por parte del Perú oficial, y de cómo la informalidad fue la casi única manera de acceder al suelo o al trabajo. Grompone (1985), por su parte, diría que nace por el intento diario de los no asalariados por mantenerse independientes. Expresando un enfoque es estratégico, porque parte de las decisiones de los trabajadores no asalariados por mantenerse independientes.

Para De Soto (1986), desde un enfoque jurídico y administrativo, señala que la causa es un Estado mercantilista que genera trabas para aumentar la formalización. Los más perjudicados serían los emergentes. Desde una mirada más culturalista, Martuccelli (2015) sostiene que la fusión social, resultado de la migración, ha construido un imaginario y proyecto común. Su mirada se caracteriza por un enfoque culturalista, ya que pretende acceder a los imaginarios de la informalidad. Durand (2007), desde una postura crítico normativa, argumenta que es consecuencia de un Estado débil, incapaz de imponer la formalidad. 
También vale la pena preguntarse por la dimensión que cada uno de estos autores desataca y a qué actor social explícitamente estudia o analiza. Así se puede ver que Quijano (1977) estudia la dominación de los "marginales" que no logran ser completamente integrados a la sociedad. Mientras que Matos Mar (1980) analiza las barriadas que han construido, de manera informal, la ciudad de Lima. En el caso de Grompone (1985), el tema cambia radicalmente: él estudia las prácticas de sobrevivencia de los autoempleados o no asalariados y las diferencias entre ellos. De Soto (1986) señala que estudia las prácticas "subversivas" de los "emprendedores" y las trabas burocráticas del Estado. Muy distinto a Martuccelli (2015), quien va detrás de la impronta de una cultura informal y del imaginario común que configura la vida cotidiana, en medio de conflictos. ¿En qué enfatiza Durand (2007) sobre la informalidad? En las perversiones de las economías no formales y sus consecuencias culturales, sociales y en el Estado.

Otra de las diferencias resulta respecto de cómo ven al Estado en estas reflexiones sobre la informalidad. ¿Qué aproximación tienen? Quijano (1977) no habla del Estado. Ésta es una entidad ausente, ya que no existe por decisión propia, sino serían el reflejo de las elites económicas nacionales e internacionales. Ese Estado es aliado del capital internacional. Matos Mar (1980) señala que el Estado es la expresión del Perú oficial, del mundo oligárquico y criollo, que es rebasado por los migrantes. El caso de Grompone (1985) demuestra que tampoco ve al Estado, sino que prioriza las prácticas cotidianas del auto empleado. Martuccelli (2015) diría que el Estado es una fuerza que le pone límites a la informalidad a través del "proyecto regulador". Para terminar, Durand (2007) le pone un especial énfasis al Estado, la explicación de la informalidad radica en su debilidad.

¿Estudian al poder en el fenómeno de la informalidad? O en todo caso, ¿qué aspecto de las relaciones de poder se analiza en sus aproximaciones a la economía informal? Para Quijano (1977) el poder se encuentra en el capital internacional que produce marginalidad en los países periféricos. Matos Mar (1980) diría que el poder está en las elites oligárquicas y criollas, que es rebatido por los migrantes. Grompone (1985), por su parte, haría referencias a prácticas de ejercicio de poder generales, ya que su mirada recae en los dueños del capital. ¿Cuál es la aproximación al poder en la producción de Hernando De Soto? Es el Estado quien ejerce poder, ya que es usado como un instrumento para excluir. En el caso de Martuccelli (1985), las relaciones de poder son elementos casi ausentes en su reflexión, enfatiza la identificación del sistema simbólico de la 
informalidad. Finalmente, Durand (2007) es el que tiene más marcada la mirada en las relaciones de poder, sobre todo al interior de la informalidad desde la "lumpen burguesía informal".

En líneas generales, como lo ha señalado Rojas (2018), las miradas sobre la informalidad peruana se diferencian en dos grandes grupos, los que de alguna forma celebran la informalidad y los críticos.

Tabla 1

Nociones generales sobre la informalidad

\begin{tabular}{cccc}
\hline \multicolumn{2}{c}{ Celebratorios } & \multicolumn{2}{c}{ Críticos } \\
\hline Liberales & Progresistas & Marxistas & No marxistas \\
& Matos Mar & Quijano & Durand \\
De So & Martuccelli & & Grompone \\
& & & \\
\hline
\end{tabular}

Fuente: Moisés Rojas (2018).

En el primer grupo de ellos, se puede identificar a los liberales liderados por De Soto. Para esta mirada, la informalidad demostraría que el esfuerzo individual crea riqueza. En ese primer grupo de los celebratorios también se encuentran a los que festejan la informalidad, pero porque sería un elemento integrador. Unos a través de la revolución urbana (Matos Mar, 1980) o a través de la revolución de la cotidianidad (Martuccelli, 2015). Ellos creen ver en la informalidad aquel factor de cohesión social.

En el otro grupo se puede encontrar a los críticos, que a su vez se subdividen en la crítica marxista, basada en la dominación del capital; y en la crítica, por un lado, de las condiciones precarias de los trabajadores autoempleados (Grompone, 1985) y, por el otro, en la crítica normativista que plantea que el Estado no es uno moderno, sino resultado de la informalidad (Durand, 2007).

\subsection{Nuestro lenguaje: tiempo y dominación}

Goerge Simmel (1986: 3) decía que "si bruscamente todos los relojes de pulsera de Berlín se pusieran a avanzar o retrasar de manera discordante, así fuera durante un máximo de una hora, toda la vida económica y social quedaría completamente descompuesta durante 
un largo tiempo". Por su parte Norbert Elías explicaba que "el individuo no inventa el concepto del tiempo por sí mismo, sino que lo aprende desde la infancia tanto el concepto del tiempo como la institución social del tiempo que le está unida de modo indisoluble" (Elías, 1989: 20). El tiempo es por un lado un estructurador social, pero además al ser un producto social, es resultado de procesos sociales diferentes. No es lo mismo el tiempo en las zonas rurales o las urbanas, en los sectores sociales altos o bajo, en las mujeres o los hombres; y no es lo mismo el tiempo en actores sociales con un régimen de trabajo estable o flexible.

Richard Sennet cuenta en lo que podríamos considerar un gran tratado del tiempo en el trabajo, cómo es que en una misma familia norteamericana -apenas en dos generaciones - se experimenta desde el tipo de trabajo: estable o flexible, una forma completamente diferente de proyectarse hacia la vida. El padre era un portero de una escala social baja pero que tenía una linealidad en el tiempo de su vida: "Lo que más me sorprendió de Enrico y su generación fue cuál lineal era el tiempo de su vida: año tras año en empleos que raramente presentaban cambios en lo cotidiano; en ese tiempo lineal, los logros eran acumulativos. [...] El portero se sentía que se convertía en el autor de su vida, y, aunque ocupaba los últimos peldaños de la escala social, ese relato le proporcionaba una sensación de respeto por su propia persona (Sennet, 2000: 14).

En cambio, el hijo, un ingeniero que recientemente inauguraba una empresa prestadora de servicio, era coaptado por la inestabilidad. "En el caso de Rico, el miedo a perder el control es fácil de comprender: tiene que ver con el manejo del tiempo. Cuando Rico les dijo a sus colegas que iba a abrir su propia consultoría, la mayoría aprobó; una consultoría parece ser el camino de la independencia”. El gran problema es que trabaja por proyectos, y al término de uno, nuevamente aparecía la necesidad de disputarse en el mercado laboral una oportunidad de generarse ingresos. Ese tipo de trabajo flexible no es solo el caso de un individuo, es el modelo actual del trabajo de la nueva economía: todo es flexible, momentáneo, circunstancial: "Las condiciones de la nueva economía se alimentan de una experiencia que va a la deriva en el tiempo, de un lugar a otro lugar, de un empleo a otro. Si pudiera establecer el dilema de Rico en términos más amplios, diría que el capitalismo del corto plazo amenaza con corroer su carácter, en especial aquellos aspectos del carácter que unen a los seres humanos entre sí y brindan a cada uno de ellos una sensación de un yo sostenible”. (Sennet, 2000: 25). 
En un escenario caracterizado por la modernidad líquida en dónde todo lo solido se diluye, el contexto que nos define proviene de un: “el trabajo humano, así como el resto de la vida humana, está partido en episodios cerrados en sí mismos”. (Bauman, 2004: 148). Asimismo, señala que: "Del universo de la construcción del orden y del control del futuro, el trabajo se ha desplazado al ámbito del juego; el acto de trabajar se parece más a la estrategia de un jugador que se plantea modestos objetivos a corto plazo sin un alcance que vaya más allá de las próximas dos o tres jugadas” (148).

Y a su vez señala que "la incertidumbre actual es una poderosa fuerza de individuación. Divide en vez de unir, y como no es posible saber quién despertará mañana en qué facción, el concepto de 'interés común' se vuelve cada vez más nebuloso y pierde todo valor pragmático" (Bauman, 2004: 158).

Pierre Bourdieu, entre los clásicos modernos de la sociología, es el que plantea una teoría del tiempo como una variable de poder entre clases sociales. En la relación de las esperanzas subjetivas de los hombres y sus posibilidades objetivas de alcanzarlos se encuentra la diferencia entre el hombre que está o no despojado de su porvenir. Cuando las expectativas y las posibilidades objetivas se rompen, se rompe el presente y el futuro. Los hombres estarían echados a su suerte: "soy como una basura arrastrada por el agua" (citado por Bourdieu, 1999: 195). El tiempo, desde el poder, plantearía la diferencia entre los que podrían construirse el futuro, y los que estarían despojados de él: "Ahora bien, en el mundo social existe una categoría, la del subproletariado, que recuerda estas condiciones al hacer aflorar lo que sucede cuando la vida se trasforma en «juego de azar» [...] y el deseo de potencia limitada que es el habitus se anula, en cierto modo, ante la experiencia más o menos duradera de la más absoluta impotencia: los psicólogos han observado que la perdida de las posibilidades asociadas a las situaciones de crisis implica el hundimiento de las defensas psicológicas, y en el caso que nos ocupa ello se traduce en una especie de desorganización generalizada y duradera del comportamiento y el pensamiento vinculada al desmoronamiento de cualquier objetivo coherente relacionado con el porvenir" (Bourdieu, 1999: 292-293).

Como señalamos en la introducción, este artículo discute la naturaleza de la informalidad precaria en la desarticulación de la ciudadanía ya que despolitiza a los sujetos instalados en ella. Nuestra hipótesis es que la informalidad hoy en día contiene a los pobres urbanos despolitizándolos al extremo. ¿No es casualidad que en Gamarra en 50 años de funcionamiento no haya habido una sola protesta laboral a pesar de su alta 
precarización? La investigación de Javier Auyero sobre la contención de la pobreza urbana es muy interesante en esa línea. El mencionado autor hace notar que, en Argentina, la espera, como fenómeno administrativo del Estado, tiene efectos diríamos devastadores en los pobres urbanos de Buenos Aires. Tiene efectos políticos, porque los despolitiza. Valga decir que, para el caso peruano, los pobres urbanos de Lima no esperan nada del Estado porque no saben cuestionarlo políticamente y no se asumen como sujetos de derechos. En su gran mayoría, ellos tratan de encontrar su salida a como dé lugar, pero por cuenta propia. Es así que, según Instituto Nacional de Estadística e Informática (INEI), en el 2017 decía que el 94.2\% de los pobres de 14 a más años de edad, trabajan en empleos informales.

Auyero, por su parte, señala que el Estado tiene al menos tres formas de contener a los pobres: "Sostengo y demuestro que para poder entender mejor la relación que existe entre la dominación de los pobres y la política de violencia colectiva, debemos prestar atención al funcionamiento simultáneo de estas tres fuerzas (puños, patadas y tentáculos) en la vida cotidiana de los desposeídos" (Auyero, 2009: 66). Los "puños visibles" es la forma en la que el Estado usa su fuerza de forma explícita; las "patadas clandestinas" son las formas que se emplean cuando el Estado contrata a "matones" a sueldo para hacer aquello que no podría hacerlo de forma directa; y los "tentáculos invisibles": "Además del puño de hierro y de las patadas clandestinas, el Estado recurre a los 'tentáculos' más blandos y menos visibles para mantener a los parias urbanos bajo control" (82).

Ulrich Beck (2009), rescatando los postulados de Karl Marx, señala que un acuerdo laboral muestra dos planos de análisis: un acuerdo que intercambia fuerza de trabajo por dinero ("te doy mi fuerza de trabajo a cambio de tan cantidad de ingresos", o "te doy esta cantidad de dinero por tu tiempo de trabajo"), y otro que llama conceptualmente la atención, el acuerdo referido al consentimiento: "El acuerdo laboral es también un acuerdo que manifiesta el consentimiento conforme al modelo de "yo, el empresario, te pago a ti y me desentiendo de los que haces con tu dinero en tu tiempo libre, en tanto que tú te desentiendes de lo que yo hago y produzco con tu fuerza de trabajo durante las horas laborales por las que te pago" (Beck, 2009: 151).

Entonces el consentimiento del acuerdo laboral hace referencia a desatender lo que esté más allá del intercambio explícito de fuerza de trabajo por dinero. En el fondo esta es la construcción social de la despolitización para el caso gamarrino. El mismo Beck 
señala que cuando ese consentimiento deja de ser automático, entonces el poder comienza a desintegrarse. En Gamarra una trabajadora puede ganar 1250 soles (350 dólares aproximadamente) mensuales vendiendo ropa al por mayor por un monto de 16 mil soles (4,600 dólares aproximadamente) diarios, y a su vez no preocuparse por el altísimo margen de ganancia del empresario contratante. Aquí se copia un extracto de la conversación que se tuvo con la vendedora:

Investigador: ¿Cuántos vendías diariamente en la tienda donde trabajabas?

Yane: Yo vendía al por mayor. Vendía 16 mil o 18 mil soles diarios.

Investigador: Era bastante, pero tú ganabas 1250 mensual. ¿Qué pensabas sobre eso?

Yane: Sí, pues. Yo solo pensaba en acabar el mes para recibir mi sueldo.

Ese es solo un ejemplo. Existen en Gamarra miles de formas en las que se expresan el consentimiento de la precariedad laboral. Conceptualmente, existe un acuerdo por el desinterés que es sostenido y mantenido por una serie de mecanismos, que es fundamental analizar y descubrir. Entonces valdría la pena preguntarse de qué forma es más conveniente investigar la forma en la que la informalidad produce sujetos despolitizados. Consideramos conveniente analizar la experiencia más concreta, en este caso la del tiempo.

Para ello recurrimos al enfoque teórico de la lógica sociológica de las asociaciones, paradigma liderado por autores como Bruno Latour. Para este grupo de académicos, la sociología ya no debería dedicarse exclusivamente a analizar las relaciones humanas entre sí. Lo no humano tendría que ser tomado en cuenta por su un impacto determinante en nuestras interacciones: "Cuando se ejerce el poder en forma duradera, es porque no está construido de vínculos sociales; cuando el ejercicio del poder tiene que depender solo de vínculos sociales, no se ejerce por mucho tiempo. Por lo tanto, cuando los científicos sociales hablan de «vínculos sociales» deberían referirse siempre a algo que tiene muchas dificultades para extenderse en el tiempo y el espacio, que no tiene inercia y debe ser negociado todo el tiempo. Precisamente por la dificultad de mantener asimetría, establecer relaciones de poder de modo duradero, imponer desigualdades es que se dedica tanto trabajo a convertir los vínculos débiles y de rápida desaparición en otros tipos de vínculos. Si el mundo social estuviera hecho de interacciones locales, tendría una especie de aspecto provisional, inestable, caótico, y no este paisaje fuertemente diferenciado que las referencias al poder y la dominación pretenden explicar [...] Cuando invocan la durabilidad de algunos agregados sociales siempre, voluntaria o 
involuntariamente, prestan a los vínculos sociales débiles la pesada carga que proviene de las masas de otras no sociales. Siempre son cosas -y ahora quiero usar está última palabra en sentido literal-las que, en la práctica, prestan su «fortaleza» a la desventurada «sociedad»". (Latour, 2008: 100-101)

Latour nos presta un punto de vista fundamental, la necesaria mirada hacia lo empírico para estudiar el poder y la exigencia de estar en el mismo terreno in situ de las interacciones, en este caso laborales para comprender desde el tiempo, las dificultades que los trabajadores gamarrinos tienen para ser críticos sobre su condición laboral, generar alguna identidad como trabajadores y emprender experiencia organizativa en defensa de sus derechos laborales.

\section{Casos de estudio}

Esta sección de artículo será a su vez divida en dos partes: las experiencias mismas del tiempo y el análisis de sus implicancias políticas.

\subsection{La experiencia del tiempo}

De los cuatro tipos de trabajadores estudiados, vemos que los que más sufren los avatares de la inestabilidad en el trabajo son los ambulantes. Ya que en gran medida dependen de la voluntad política de turno, de sacarlos o no de las calles. "Nuestra vida depende de un hijo", dice uno de los entrevistados. Pero no son los únicos, todos los demás, tanto los jaladores, como los talleristas y las vendedoras, tienen una inestabilidad marcada en su trabajo. No tener un mínimo de estabilidad desarraiga. Ellos no están sujetos al rol que tienen al punto de hacerse dueños y buscar mejoras. Por el contrario, se sienten de paso, aunque luego cuando hagan el recuento, lleven más de 5 años en el mismo trabajo. Ana Arjona (2017) recientemente, a propósito de los grupos beligerantes de Colombia, descubrió que los que pensaban quedarse en el lugar cuando tomaban ciertos territorios colombianos se preocupaban por cuidar el espacio, generar buenas relaciones con el entorno. Su horizonte temporal de permanencia tuvo una consecuencia política: el cuidado del lugar y el compromiso con el mismo. Mientras que los grupos beligerantes que solo estaban de paso "pateaban el tablero", destruían el lugar, prácticamente abrían

${ }^{2}$ Énfasis añadidos 
fuego a diestra y siniestra. La misma lógica es completamente replicable para el caso de Gamarra.

La jornada laboral también es diferente entre ellos. Para el caso de los ambulantes es altamente flexible dado que ellos mismos deciden cuantas horas del día trabajar. Los jaladores tienen una jornada más flexible ya que muchos de ellos son empleados, por lo que tienen que sujetarse a un horario de trabajo. Los talleristas y las vendedoras, en cambio, tienen un horario fijo de trabajo, que suele ser de 9 am a 7 pm. En total, 10 horas de trabajo al día. Cada uno de estos trabajadores al tener sus propias dinámicas temporales, tienen enormes dificultades para encontrarse y siquiera pensar una acción colectiva.

La estructuración el día a día, es decir, la rutina de su trabajo, es medianamente estructurado para el caso de los ambulantes y jaladores, y medianamente estructurado para los talleristas y vendedoras. En muchos casos observados, la poca estructuración de la rutina es vista como un síntoma de libertad y comodidad. Muchos de los trabajadores han tenido experiencias de alta precarización previamente a trabajar en Gamarra, por lo que la no presión y control, es visto como una ventaja que valoran.

Es importante ver qué tan marcada es la distancia entre el tiempo de "trabajo" y "no trabajo". Es decir, si en el tiempo del trabajo predominantemente hacen labores propias del trabajo. O si es que en el tiempo del trabajo se realizan labores personales o familiares. Para el caso, los ambulantes y los jaladores tienen un límite borroso. Su mayor autonomía en el trabajo los hace realizar labores personales mientras trabajan. La situación es diferente pare el caso de los talleristas y las vendedoras. En ellos hay una alta diferenciación entre el tiempo del "trabajo" y el del "no trabajo". Lo que está estrechamente vinculado con la autonomía en el manejo del tiempo. Igualmente, los ambulantes y los jaladores son más autónomos; y los talleristas y las vendedoras son menos autónomos.

A su vez, la relación con el futuro es muy heterogénea. Nadie tiene una actitud realmente planificadora sobre el futuro que nos hace recordar a Bourdieu sobre el despojo del futuro: "soy como una basura arrastrada por el agua". Que no ex extremo en estos casos, porque ellos sueñan y especulan, pero en términos reales es poca la capacidad de, por ejemplo, ahorrar dinero y encaminar sus objetivos de poner un negocio, que es típico objetivo que tienen los trabajadores gamarrinos. Lo que dicho sea de paso agrava la situación. Los trabajadores gamarrinos no critican el abuso de su situación ni el 
desempeño de sus empleadores, sino que pretenden en algún momento tener su rol en el comercio o la producción.

Sobre el pasado, hay que decir que estos esquemas de un pasado compartido, que fue ampliamente investigado por los estudiosos de las migraciones, el trabajo de campo revela que dicha situación está cambiando. Antes se decir que los informales de Lima, en realidad migrantes, desempeñaban estrategias colectivas de sobrevivencia con sus pares cuyos orígenes eran los mismos que los suyos. Gamarra hoy está en una etapa diferente. Los ambulantes en cuanto a su pasado son muy heterogéneos, y los jaladores talleristas y vendedoras son mediadamente heterogéneos.

\section{Tabla 2}

Tipos de trabajadores, según experiencia del tiempo

\begin{tabular}{|c|c|c|c|c|}
\hline Ejes & Ambulantes & Jaladores & Talleristas & Vendedoras \\
\hline $\begin{array}{c}\text { Estabilidad } \\
\text { laboral }\end{array}$ & Alta incertidumbre & $\begin{array}{c}\text { Mediana } \\
\text { incertidumbre }\end{array}$ & $\begin{array}{c}\text { Mediana } \\
\text { incertidumbre }\end{array}$ & $\begin{array}{c}\text { Mediana } \\
\text { incertidumbre }\end{array}$ \\
\hline $\begin{array}{c}\text { Jornada de } \\
\text { Trabajo }\end{array}$ & Altamente flexible & $\begin{array}{c}\text { Medianamente } \\
\text { flexible }\end{array}$ & $\begin{array}{c}\text { Exiguamente } \\
\text { flexible }\end{array}$ & $\begin{array}{c}\text { Exiguamente } \\
\text { flexible }\end{array}$ \\
\hline $\begin{array}{c}\text { Rutina de } \\
\text { trabajo }\end{array}$ & $\begin{array}{c}\text { Medianamente } \\
\text { estructurado }\end{array}$ & $\begin{array}{c}\text { Medianamente } \\
\text { estructurado }\end{array}$ & $\begin{array}{c}\text { Altamente } \\
\text { estructurado }\end{array}$ & $\begin{array}{c}\text { Altamente } \\
\text { estructurado }\end{array}$ \\
\hline $\begin{array}{c}\text { Nivel de } \\
\text { diferenciación } \\
\text { entre el } \\
\text { "trabajo" y el } \\
\text { "no trabajo" }\end{array}$ & $\begin{array}{c}\text { Baja } \\
\text { diferenciación }\end{array}$ & $\begin{array}{c}\text { Baja } \\
\text { diferenciación }\end{array}$ & Alta diferenciación & $\begin{array}{c}\text { Alta } \\
\text { diferenciación }\end{array}$ \\
\hline $\begin{array}{c}\text { Autonomía del } \\
\text { tiempo }\end{array}$ & Alta autonomía & Alta autonomía & Baja autonomía & Baja autonomía \\
\hline $\begin{array}{l}\text { Actitud hacia } \\
\text { el futuro }\end{array}$ & $\begin{array}{c}\text { Mediana } \\
\text { planificación }\end{array}$ & Baja planificación & $\begin{array}{c}\text { Mediana } \\
\text { planificación }\end{array}$ & $\begin{array}{c}\text { Mediana } \\
\text { planificación }\end{array}$ \\
\hline Pasado común & $\begin{array}{l}\text { Exiguamente } \\
\text { homogéneo }\end{array}$ & $\begin{array}{c}\text { Medianamente } \\
\text { homogéneo }\end{array}$ & $\begin{array}{c}\text { Medianamente } \\
\text { homogéneo }\end{array}$ & $\begin{array}{c}\text { Medianamente } \\
\text { homogéneo }\end{array}$ \\
\hline
\end{tabular}

Fuente y elaboración: Moisés Rojas (2018) 


\subsection{Consecuencias políticas}

¿Qué consecuencias políticas tiene todo ello? Hemos tratado de sintetizar la experiencia del tiempo y su correlato político. Así tenemos lo siguiente:

- Una experiencia del tiempo que implica el desgaste del cuerpo por la larga duración del trabajo realizado, ocasiona un desgaste físico y una despolitización de los sujetos involucrados en las actividades informales. Naturalmente ello genera una futura dependencia. Esta experiencia es típica en el caso de los talleristas. Se suelen quejar de las secuelas por estar horas de horas sentados en la misma posición, lo que implica daño en la columna y en la visión.

- Una experiencia de alta rotación laboral, genera un desarraigo en sus trabajos. No sienten una afinidad con sus trabajos. No se apropian de él, ni le encuentran sentido a arreglar el entorno, porque sencillamente no les pertenece. Esto es muy típico en los jaladores. Ellos se sienten de paso, aunque vayan más de cinco años desempeñándose como jaladores.

- Una percepción de estabilidad que recae en la alta demanda de trabajadores. Muchos de los trabajadores sienten que pueden tener rápidamente empleo si es que se van de su actual empleo dada la alta demanda de trabajo en Gamarra. Eso hace que muchos de ellos no traten siquiera de solucionar la precariedad laboral actual. "Si tienes problemas, te vas, siempre hay otras tiendas que te van a llamar".

- Gran variedad de ciclos que generan tiempos de menos trabajo. Llama la atención que, por ejemplo, las vendedoras, sientan que no hacen mucho, dado que, en tiempos de caída en las ventas, se dedican casi únicamente a estar sentadas. Gamarra temporalmente funciona por "campañas" (Navidad, Año Nuevo, Día de la Madre, Día del Padre, inicio de clases escolares). En el resto de los meses, las ventas caen estrepitosamente. Estos ciclos generan que nadie se sienta seguro, porque en cierto tiempo, la demanda de trabajadores caerá, y en los momentos de menos actividad y de menos carga laboral, las vendedoras sienten que no hacen mucho, no valoran lo suficientemente su trabajo.

- Existen estímulos para valorar la inestabilidad, como la que viven los destajeros talleristas, que recién un mejor sueldo si trabajan en breves periodos de tiempo. Muchos talleristas quieren trabajar como destajeros dadas las mejoras en los 
ingresos. Pero la consecuencia perversa es el individualismo y la alta competencia.

- Los mismos talleristas que inician sus labores en tal función, ven su precariedad como una etapa de aprendizaje. "Es una etapa necesaria", señalan. Este tipo de discurso hace incuestionable sus condiciones de precariedad. Al respecto, resulta pertinente el siguiente texto: "La temporalidad con que es pensada la "temporalidad" laboral se resumen en una frase: "Por un tiempito nomás". La primera idea suele ser justamente esa: se viene con un propósito limitado, buscando ahorrar una suma determinada, con la idea de volver lo antes posible con "un pequeño capital". Esa contradicción de tiempo es la que anima sacrificios descomunales" (Gagó, 2013: 190).

- La jornada de trabajo es larga, parte del día permanecen en él. Tanto que no hay tiempo para sí mismos. Trabajan incluso los domingos, que, supuestamente, seria tiempo para ellos, apenas tienen un tiempo mínimo para descansar e iniciar nuevamente la semana de trabajo. El caso de las madres solteras es más grave, dado que además de sus labores en Gamarra, usan el tiempo restante para atender las labores del hogar.

- Experiencia pasada altamente precaria, hace que a actual precariedad sea relativizada. Sienten que su actual trabajo, aunque es precario, es "el mal menor". Lo que hace más tolerable la precariedad y con ellos menos cuestionable.

- Libre decisión de la jornada tiene dos implicancias: cuando se sobrecargan, expresan una alta presión sobre sí mismos; y cuando la carga es limitada porque ya alcanzaron el dinero que necesitaban, no hay acumulación. No hay ahorro.

- Las rutinas altamente estructuradas o nulamente estructuradas generan diferentes incidencias. La primera socializa la subordinación y la segunda, sensación de libertad, lo que hace que valoren su precariedad.

- A diferencia de otras épocas, la actual experiencia gamarrina, implica múltiples historias del pasado. Rara vez hay un pasado común que los cohesione: "La diversificación notable, sin embargo, no nos impide ver semejanzas entre los casos estudiados. Quizá el común denominador más importante resida precisamente en la capacidad de imprimir a una migración individual una coherencia grupal. Todos 
los migrantes investigados muestran que son parte de conjuntos mayores que los condicionan en su desarrollo urbano" (Golte y Adams, 1990: 20).

- Igualmente, el futuro es individual. Tienen objetivos particulares, por lo que no ven la necesidad de agruparse. Tienen que sobrevivir como puedan, pero esta sobrevivencia no está sola y aunque existe pesimismo y un gran peso inercial, existe también una suerte de reconocimiento de la agencia y la confianza en la fuerza del individuo: la persona tendría cierto control sobre su destino.

\section{Conclusiones}

Se ha demostrado que la informalidad tiene desde la experiencia del tiempo una serie de implicancias de despolitización y también para la desciudadanización, aquí los derechos civiles, políticos y sociales son fragmentados y desaparecidos (básicamente los sociales), en la maquinaria del desarraigo del tiempo y del trabajo. Los informantes no hacen referencia alguna a la estructura política social neoliberal impuesta por los capitalistas chupacabras (las élites neoliberales peruanas en su expresión fujimorista), asimismo no mencionan sus derechos sociales, se consideran como sujetos sin derechos, lo que expresa la despolitización de su condición humana y ciudadana, así el sujeto a no tener derechos se ubica perfectamente en el trabajo informal del desarraigo que los despolitiza totalmente. En ese sentido, valdría la pena pensar si efectivamente es un problema real para las elites de Perú, o si lo son para las elites de los países que tienen altos niveles de informalidad laboral. Desde la experiencia del tiempo, los trabajadores son desarraigados al punto de no echar raíces y apropiarse de sus trabajos, condición fundamental para asumir una posición crítica y transformación. El modelo económico peruano no ha sido cuestionado en absoluto.

De los últimos cinco presidentes, uno ha estado preso, otro tiene orden de detención, otro vive fuera del país huyendo de enfrentar a la justicia, y otro se suicidó para evitar una detención. Ha pasado lo peor que uno puede imaginarse con las elites políticas del país, pero no se cuestiona el modelo neoliberal que ha implementado el Perú desde los años 90’s. ¿No será que tiene que ver con que los principales afectados del modelo no tienen una voz activa y tiene exigua capacidad de ejercicio político?

Preguntarse por las implicancias políticas de la informalidad precaria vuelve a un debate sobre el trabajo que hace años se ha dejado de lado por la caída del paradigma 
marxista en las ciencias sociales. Sin embargo, los noveles de precariedad laboral no solo en América Latina, nos obligan a investigar en las implicancias políticas de la precariedad. El trabajo es político y su alta precarización lo es aún más. Asimismo es importante señalar la ausencia de trabajos académicos y gubernamentales que traten sobre la relación entre ciudadanía e informalidad, relación que en este caso es antitética y contradictoria, en la revisión hemerográfica realizada no existen trabajos al respecto lo cual dice mucho acerca de la hegemonía del discurso neoliberal en el Perú, un país que aún no ha procesado completamente la guerra civil por la que atravesó en la década de los ochentas y noventas y que tampoco ha procesado adecuadamente el impacto del autoritarismo fujimorista en la constitución de lo político. La despolitización de los trabajadores informales es entonces un síntoma de un fenómeno mayor, el de una sociedad y de un estado neoliberalizados en dónde la política ni siquiera es vista como un asunto importante, lo importante es mantener el sueño de la libertad dentro del mercado, aunque sea solamente una ilusión. Hemos pasado de ciudadanos a consumidores/trabajadores, no nos realizamos en la política sino en el lugar y Gamarra representa finalmente el tiempo del mercado, el de la modernidad líquida.

\section{Referencias}

Arjona, A. (2017). Rebelocracy: A theory of social order in civil war. Kellogg Institute for International Studies. Working Paper \#422. Recuperado de: https://kellogg.nd.edu/sites/default/files/working_papers/422_0.pdf consulta realizada el 5 de junio del 2019.

Auyero, J. (2009). "Pacientes del Estado". Un reporte etnográfico sobre la espera de la gente pobre. Recuperado de: http://sites.google.com/site/javierauyero/javierauyero .

Bauman, Z. (2004). Modernidad líquida. Buenos Aires: Fondo de Cultura Económica.

Beck, U. (2009). La sociedad del riesgo global. Madrid: Siglo XXI Editores.

Bourdieu, P. (1999). Meditaciones pascalianas. Barcelona: Editorial Anagrama.

Camerón, M. y Luna, J. (2010). Democracia en la región andina: diversidad y desafíos. Lima, IEP. (América Problema, 30). Dirección electrónica: http://biblioteca.clacso.edu.ar/Peru/iep/20170327045428/pdf_164.pdf, fuente consultada el 15 de abril del 2019. 
De Soto, H. (1987). El otro sendero. La revolución informal. Lima: Instituto Libertad y Democracia.

Durand, F. (2007). El Perú fracturado: formalidad, informalidad y economía delictiva. Lima: Fondo Editorial del Congreso del Perú.

Gálvez, A. y Luque, J. (2019). Capitalismo de chupacabras en una era post-política y post-migratoria. Huellas de la Migración, 4(7). Universidad Autónoma del Estado de México (UAEM). Pp. 109-138.

Golte, J. y Adams, N. (1987). Los caballos de Troya de los invasores. Lima: Instituto de Estudios Peruanos.

González, E. y Del Pozo, J. (2012). Lima, una ciudad policéntrica. Un análisis a partir de la localización del empleo. Investigaciones Regionales - Journal of Regional Research, (23), 29-52.

Gray, J. (1993). Hayek: El orden espontaneo en las sociedades post comunistas en transición. Estudios Públicos. Chile. No. 50. Pp. 131-149. Dirección electrónica: https://www.cepchile.cl/cep/site/docs/20160303/20160303183345/rev50_gray.p df, fuente consultada el 12 de junio del 2019.

Grompone, R. (1985). Talleristas y vendedores ambulantes en Lima. Lima: DESCO.

Hart, K. (1973). Informal Income Opportunities and Urban Employment in Ghana. The Journal of Modern African Studies, I, I, pp. 61-89. Cambridge University Press. England, dirección electrónica: https://www.sv.uio.no/sai/english/research/projects/anthropos-and-thematerial/Intranet/economic-practices/reading-group/texts/hart-informal-incomeopportunities-and-urban-employment-in-ghana.pdf, fuente consultada el 12 de julio del 2019.

\section{INSTITUTO NACIONAL DE ESTADÍSTICAS E INFORMACIÓN Y MINISTERIO} DEL TRABAJO Y PROMOCIÓN DEL EMPLEO (2017). Encuesta nacional de hogares sobre condiciones de vida y pobreza 2016. Metodología actualizada. Lima: INEI, MTPE-Dirección General de Políticas de Inspección del Trabajo.

Latour, B. (2008). Reensamblar lo social. Buenos Aires: Manantial.

Latour, B. (2001). La esperanza de Pandora: ensayo sobre la realidad de los estudios de la ciencia. Barcelona: Gedisa. 
"Estamos de paso". Informalidad y ciudadanía precaria como proceso de despolitización: El caso del emporio comercial Gamarra en Lima (2012-2018)

Latour, B. (1998). "La tecnología es la sociedad hecha para que dure”. En: Domènech, Miguel y Tirado, Francisco (Comps.). Sociología simétrica: ensayos sobre ciencia, tecnología y sociedad (pp. 109-142). Barcelona: Gedisa.

Latour, B. y Pasquele, G. (2008). Las atmósferas de la política: diálogos sobre la democracia. Madrid: Editorial Complutense.

Matos Mar, J. (2012). Perú, Estado desbordado y sociedad nacional emergente. Lima: Universidad Ricardo Palma.

Matos Mar, J. (1980). Desborde popular y crisis del Estado. Lima: IEP.

Martucelli, D. (2015). Lima y sus arenas. Poderes sociales y jerarquías culturales. Lima: Cauces Editores.

Marshall, T.H.S y Bottomore, T. (1992). Ciudadanía y clase social. Alianza Editorial, Madrid, España.

Pease, H. (2003). La autocracia fujimorista. Del Estado intervencionista al Estado mafioso. Pontificia Universidad Católica del Perú, Fondo de Cultura Económica (FCE), Lima, Perú. Pp. 1-404.

Quijano, A. (1998). La economía popular y sus caminos en América Latina. Lima: Mosca Azul Editores, CEIS-CESCOSAM.

Quijano, A. (1977). Imperialismo y “marginalidad” en América Latina. Lima: Mosca Azul Editores.

Rojas, M. (2018). “Dispersos” y “desarraigados”. Las consecuencias políticas del trabajo informal precario. Tesis de maestría en la Pontificia Universidad Católica del Perú (PUCP).

Salazar-Xirinachs, José y Chacaltana. (2018). Políticas de formalización en América Latina. Avances y desafíos. Perú: Organización Internacional del Trabajo (OIT). Oficina Regional para América Latina y el Caribe, pp. 484. Revisado en: https://www.ilo.org/wcmsp5/groups/public/---americas/---ro-

lima/documents/publication/wcms_645159.pdf, fuente consultada el 12 de abril del 2019.

Sennet, R. (2000). La corrosión del carácter. Consecuencias personales del trabajo en el nuevo capitalismo. Barcelona: Editorial Anagrama.

Simmel, G. (1986). "Las grandes ciudades y la vida del espíritu”. En: Cuadernos Políticos, (45), pp. 5-10. México D. F.: Editorial Era. 
Rojas, M.; Luque, J. 